2017-06-26

\title{
A Cross-Cultural Study of Risky Online Self-Presentation
}

\author{
White, CM
}

http://hdl.handle.net/10026.1/10015

10.1089/cyber.2016.0660

Cyberpsychology, Behavior, and Social Networking

All content in PEARL is protected by copyright law. Author manuscripts are made available in accordance with publisher policies. Please cite only the published version using the details provided on the item record or document. In the absence of an open licence (e.g. Creative Commons), permissions for further reuse of content should be sought from the publisher or author. 
A cross-cultural study of risky online self-presentation

White Claire M., Cutello Clara A., Gummerum Michaela, and Hanoch Yaniv.

Cyberpsychology, Behavior, and Social Networking. June 2017, ahead of print.

https://doi.org/10.1089/cyber.2016.0660

A cross-cultural study of risky online self-presentation

Claire M. White, Clara A. Cutello, Michaela Gummerum and Yaniv Hanoch School of Psychology

University of Plymouth

Address correspondence: Claire White, School of Psychology, University of Plymouth, Plymouth, UK, PL4 8AA. Email: claire.white@ plymouth.ac.uk 
A cross-cultural study of risky online self-presentation

\begin{abstract}
The use of social media is pervasive amongst young adults. However not all posted content is beneficial to their self-presentation, but can have negative and damaging consequences. This study investigated how individual differences in self-monitoring and impulsiveness influence risky online self-presentation in British and Italian samples. British participants $(n=88)$ were more likely to post comments and images related to their alcohol and drug use, while Italian $(n=90)$ participants posted more offensive content and personal information. High self-monitoring and high impulsiveness was positively predictive of risky self-presentation online regardless of nationality, highlighting the normative influence of social media culture, and the influence of both spontaneous and deliberative behaviour on posting inappropriate content online. These novel insights regarding the way young adults present themselves on social network sites could help explain differences in self-presentation.
\end{abstract}

Key words: Impulsivity; risk taking; social network sites; self-presentation; selfmonitoring 
Social Networking Sites (SNS) are extremely popular among adolescents and young adults, providing them with a unique platform to enhance their social development ${ }^{1}$, increase social capital ${ }^{2}$, and find academic and employment opportunities. However, not all usergenerated content on SNSs is appropriate or even legal. Young adults often use SNSs to share images of alcohol and drug consumption ${ }^{3,4}$, disseminate personal information (e.g. credit card details) ${ }^{5,6}$, and post (semi-)nude selfies ${ }^{7}$. Since young internet users from different European countries have been shown to behave differently and experience different risks online ${ }^{8}$ this study investigated individual and cultural differences in risky online selfpresentation in the U.K. and Italy.

Most users report that they would be happy for their friends and family to view their SNS posts. However, many worry about future employers or strangers gaining access to this information ${ }^{9}$. In fact, almost $40 \%$ of British, Canadian, and US companies now use SNSs to check candidates' suitability ${ }^{10,11,12}$. Individuals have been fired from jobs ${ }^{13}$, resigned from public office ${ }^{14}$ and suspended from higher education ${ }^{15}$ because of disparaging social media posts. At the same time, researchers ${ }^{16}$ have argued that positive self-presentation on SNSs is more vital than ever due to the "nonymous" ${ }^{16}$ nature of these sites. Indeed, self-presentation management, successfully portraying a positive image of oneself while avoiding creating an unfavourable one, appears to run counter to posting potentially damaging information online 17. Therefore, it is vital to understand the processes that might underlie the propensity to selfdisclose personal and unfavourable information on SNSs.

It is debated how much (cognitive) effort individuals invest in online self-presentation. Some suggest that postings on sites such as Instagram or Twitter are spontaneous ${ }^{16}$ and may 
A cross-cultural study of risky online self-presentation

be linked to impulsivity ${ }^{3}$. Risky online posts on SNSs, therefore, might be driven by individuals not spending time and cognitive efforts on thinking about the (negative) effects of those posts. Others ${ }^{16}$ indicate that online personas, particularly on dating sites, are carefully crafted and edited until an ideal-self is presented, suggesting a fully deliberated approach. One fundamental factor in such a deliberate approach to online self-presentation might be self-monitoring, typically defined as an individual's ability to regulate their physical and emotional self-presentation such that situationally appropriate, favourable self-images are maintained ${ }^{18}$. Individuals high in self-monitoring adapt the information they present of themselves based on social and interpersonal cues and norms. Thus, high self-monitors adjust their self-presentation to fit with what they perceive to be favoured by others in a particular situation. Conversely, low self-monitors maintain a consistent self-image more akin with their 'true' selves, personality and beliefs ${ }^{18}$. Individuals low in self-monitoring are also typically more impulsive ${ }^{18}$, probably because they do not have to adapt their self-image to different situations.

Here, we investigated whether risky online posting on SNSs are associated with spontaneous (i.e., impulsive) or deliberate (i.e., self-monitoring) processes. Previous research indicates that impulsivity is positively related to risky online self-disclosure ${ }^{3}$. However, since high self-monitors strive to amend their self-presentation in line with perceived social and situationally-appropriate norms ${ }^{18}$, people high in self-monitoring might also be more likely to post risky information on SNS, because they perceive this to be the "right thing to do" in these situations.

While previous research highlighted cultural differences in the perception and use of social media $21,22,23,24,25$ and internet performance and ability ${ }^{26}$, cultural variations in risky online self-presentation and its underlying processes have rarely been considered. Karl et al. ${ }^{19}$ argued that cultural variations, based on Hofstede's ${ }^{27}$ six cultural dimensions, could 
A cross-cultural study of risky online self-presentation

elucidate differences in online risky self-presentation. American, compared to German, students were more likely to post inappropriate material (e.g. sexual content) on their profiles, due in part to the lower Uncertainty Avoidance and higher Individualist culture in America ${ }^{28}$. We compared the behaviour of young adults from Italy and the U.K. British culture scores low on Uncertainty Avoidance resulting in a relaxed attitude towards uncertainty and an acceptance to take things as they come ${ }^{27}$. Conversely, Italian culture scores high on Uncertainty Avoidance, indicating intolerance for beliefs and behaviours outside the norm and more rigid codes of conduct. Additionally, the British high score on the Indulgence dimension is associated with an inclination to gratify desires for the purposes of fun and enjoyment, while Italy's lower score on this dimension is associated with a suppression of gratification to preserve social normative expectations ${ }^{27}$.

In sum, we hypothesised that (i) people high in impulsiveness would display higher rates of risky online self-presentation; (ii) participants high in self-monitoring should engage in higher rates of risky online self-presentation; (iii) there would be an interaction between selfmonitoring and impulsiveness; (iv) due to their higher cultural scores on Indulgence and lower scores on Uncertainty Avoidance British participants would score higher on impulsivity compared to Italians. Therefore, impulsivity would be a stronger predictor of risky online self-presentation for British participants; (v) due to their higher cultural scores in Uncertainty Avoidance and lower scores in Indulgence, Italians should show higher selfmonitoring than British participants. Consequently, self-monitoring should be a stronger predictor of risky online self-presentation for Italian participants. We further included a SelfPresentation measure and time spent online as control variables.

\section{Method}

\section{Participants}

One hundred and seventy-eight British $\left(N=88, M_{\text {age }}=20.87\right.$ years, $S D=4.92,73$ 
A cross-cultural study of risky online self-presentation

Female $)$ and Italian $\left(N=90, M_{\text {age }}=22.37\right.$ years, $\mathrm{SD}=2.06,57$ Female $)$ participants were recruited to complete an online questionnaire. All were undergraduate students, who received course credit for their participation.

\section{Materials}

Social Network Use. Participants indicated which of the top 10 social networking sites in Britain, and Italy ${ }^{29}$ they frequented and how many hours per week they used each site.

Online Risk Exposure. To measure risky online self-presentation we designed a risk exposure scale containing 19 items relating to potentially risky images or texts that individuals could post online, such as drug and alcohol use, sexual content, personal details, and offensive material. This scale was pilot tested in the U.K. and Italy, and any ambiguous items were reworded for clarity. Participants indicated whether they had engaged in these activities in the past by responding No (0), Don't Know (1) or Yes (2). If individuals responded 'Don't Know' or 'Yes' they were asked to state which SNSs these postings were on. A risk exposure score, engagement $\mathrm{x}$ number of SNSs, was calculated. The items were then categorized by five independent coders into four content areas: Alcohol/Drugs, Sexual, Personal, and Offensive Content Exposure (Cohen's $\kappa=.84)$.

The Values Survey Module (VSM) ${ }^{30}$ assessed cultural differences on six dimensions: Power Distance, Individualism vs. Collectivism, Masculinity vs. Femininity, Uncertainty Avoidance, Long- vs. Short-Term Orientation, and Indulgence vs. Restraint. The 24 items were scored on a 5-point scale (scored 1-5), and country scores on each dimension calculated using specific index formulae $\left(\right.$ see $\left.^{30}\right)$.

Self-Presentation. The Psycho-social Aspects of Facebook Use (PSAFU) Scale ${ }^{31}$ evaluates a range of psychological behaviours on Facebook. We utilised only the SelfPresentation sub-scale, which contained eight items. We tailored some items to represent social media use in general by removing reference to Facebook specifically. Participants 
A cross-cultural study of risky online self-presentation

responded on a 5-point scale $(1=$ It doesn't refer to me at all to $5=$ It completely refers to $m e)$ and scores for the eight items were summed $(\alpha=.87)$.

The Self-Monitoring Scale ${ }^{18}$ measured individuals' active control of their behaviour and the way they presented themselves to others. Participants answered "True" or "False" to 18 statements. Each statement was predefined as requiring a specific response to reflect a high self-monitoring individual. As such, 10 statements were keyed as False and eight statements were keyed as True. High self-monitors answered in the keyed direction (1) while low self-monitors answered in the opposite direction (0). Because the answer options on this scale were binary, we calculated the polychoric ordinal alpha $(\alpha=.80)^{32}$

The Eysenck Impulsivity Inventory ${ }^{33}$ Impulsiveness sub-scale asked participants to answer Yes (1) or No (0) to 19-items $(\alpha=.82)$.

\section{Procedure}

The questionnaire was first produced in English before being translated and backtranslated to from Italian to English. All participants provided consent before completing the questionnaire online.

\section{Results}

\section{Descriptive analyses}

British participants used significantly more SNSs but did not spend more time on these sites each week compared to Italian participants (Table 1). Italians scored considerably higher on Masculinity and Uncertainty Avoidance, while the British showed a higher score for Long-term Orientation and Indulgence (Table 2).

A series of independent samples $t$-tests (Table 1) with risky self-presentation (alcohol/drug; sexual; personal; offensive) as the dependent variable and nationality (British; Italian) as the independent variable was conducted. British participants posted significantly more images/comments containing alcohol and drug content than Italian participants. Italian 
A cross-cultural study of risky online self-presentation

participants posted significantly more personal information and offensive content than British participants. There was no significant cultural difference for sexual content postings.

A series of independent samples $t$-tests (Table 3) revealed no significant cross-cultural difference on the self-monitoring scale. However, British participants scored significantly higher on Self-Presentation and marginally significantly higher on impulsiveness.

A full breakdown of correlations for each country can be seen in Tables 4 and 5. For both British and Italian participants, weekly time spent on SNSs was correlated with the number of SNSs used and with sexual content disclosure, and alcohol/drug content disclosure for the Italian participants. For both samples, posting offensive content was significantly related to posting risky content in the other three content areas. The impulsiveness scale was significantly positively correlated with alcohol/drug, personal information and offensive content postings for the British participants, and with alcohol/drug postings and offensive content for the Italian participants. Scores for Self-Presentation were negatively significantly correlated with offensive content postings for the British sample.

Self-monitoring was significantly related to risky online postings in both samples. For British participants, significant correlations were found for alcohol/drug content, sexual content and personal content. For Italian participants there was a significant relationship between self-monitoring and alcohol/drug content, personal content, and offensive content.

\section{Predicting risky online self-disclosure}

Generalized Estimating Equations were used to fit a Poisson regression with a natural log link function with risky online postings on SNSs as the dependent variable. The predictor variables were Nationality (Italy, U.K.), Risk Type (Alcohol/Drug Use, Sexual Content, Personal Information, Offensive Content), Self-Monitoring, Impulsiveness, Self-Presentation, and Weekly Time Spent Online. We included the predicted main effects of Impulsiveness, Self-Monitoring, and Nationality as well as the predicted interaction effects of Impulsiveness 
A cross-cultural study of risky online self-presentation

x Self-Monitoring, Nationality x Impulsiveness, and Nationality x Self-Monitoring. Furthermore, we added Risk Type, Self-Presentation, and Weekly Time Spent Online as control variables. Since our descriptive analysis revealed country differences in risky online postings by risk type, we additionally entered the interactions of Nationality x Risk Type $\mathrm{x}$ Impulsiveness and Nationality x Risk Type x Self-Monitoring.

Table 6 displays the parameter estimates and the 95\% Wald confidence intervals for all main and interaction effects. Impulsiveness $(O R=1.07, p=.04)$ and self-monitoring $(O R$ $=1.16, p=.01)$ positively predicted risky online postings. Overall, Italians $(O R=1.54, p=$ .02) posted more risky content than U.K. participants. Those participants who spent more time online showed more risky online self-presentation $(O R=1.02, p=.02)$. Risky online postings differed by risk type; participants took significantly less risks when giving out personal information $(O R=.51, p<.01)$, and significantly more risks when posting offensive content $(O R=3.86, p<.01)$. A three-way interaction also revealed that U.K. participants who scored higher in self-monitoring posted significantly less offensive content $(O R=1.18, p=$ $.01)$

\section{Discussion}

Social media use is pervasive among young adults ${ }^{34}$, yet with so much emphasis on maintaining a good online reputation, little is known about why some individuals post potentially negative or damaging comments and images. To address this important question, we investigated psychological factors which may influence risky online activity, namely selfmonitoring, and impulsiveness. We expected that higher impulsiveness and self-monitoring would predict higher rates of risky online postings. Concordant with our predictions, and with earlier findings ${ }^{3,6}$, our data indicated that impulsiveness was predictive of online risky postings. This is very much in line with previous research on impulsivity and online (e.g., 
posting illegal content ${ }^{3}$, problematic internet use ${ }^{35,36}$ and internet addiction ${ }^{37}$ ) and offline risk-taking (e.g., alcohol and drug use, smoking, risky sexual behaviour ${ }^{38}$ ). Our findings extend this research to the study of risky online self-presentation.

Self-monitoring was also positively predictive of risky online posting activities. Superficially, posting details of drug consumption or sexually provocative images may not appear appropriate when considering that an individual's post is visible to current and/or potential employers ${ }^{16}$. However, people high in self-monitoring behave in what they perceive is a situationally appropriate way ${ }^{18}$, and online identity is argued to be a product of the online social environment ${ }^{16}$. Consequently, if individuals perceive risky postings as common, or the norm, on SNSs they may follow these normative expectations ${ }^{7}$. Furthermore, people are often driven by the pleasure related to their self-disclosure (i.e. likes) despite (or maybe due to) the potential risks involved ${ }^{39}$. Some ${ }^{16}$ have argued that individuals present themselves on SNS in ways that are congruent with both the standards of the online spectators as well as the value that those spectators can bring to the individual. High self-monitoring SNS users often experience 'audience segregation difficulties' ${ }^{40}$ however and are unable to effectively distinguish between groups of spectators and what is appropriate self-presentation. Thus, posts that may be highly inappropriate on a career networking site may seem situationally appropriate on Facebook where this behaviour may be the norm. Indeed, many Facebook users utilise provocative pictures in order to be noticeable on SNSs ${ }^{16}$, or to gain positive attention from friends ${ }^{41}$. Our high self-monitoring participants clearly used SNSs as platforms to selfpresent themselves as 'cool' where this behaviour was valued and rewarded. Consequently, future research should more closely investigate how different risky posting behaviours are exhibited across different SNSs in relation to self-monitoring.

British participants scored higher on impulsiveness, lower on self-monitoring, lower on Uncertainty Avoidance, and slightly higher on Indulgence, compared to Italian participants. 
A cross-cultural study of risky online self-presentation

However, our data did not support our hypotheses that the processes underlying risky online posting (i.e., impulsiveness, self-monitoring) differed by country. Thus, we can cautiously conclude that the psychological processes affecting risky online behaviour might be similar across culture. This would be in line with research on offline risk-taking, which has shown strong similarities in the factors influencing risk-taking across cultures $42,43,44$.

Our data did, nonetheless, reveal differences by country for the types of risky selfpresentation. U.K. participants were more likely to post images/comments of alcohol/drug use, whereas Italian participants posted personal information and offensive content. These findings could be attributed to the binge drinking culture in the U.K. ${ }^{45}$ and by the Italian's high score on the Masculinity dimension of the VSM ${ }^{27}$ which, coupled with low Uncertainty Avoidance, produce individuals who are highly passionate, emotional and expressive of their opinions. As such these social norms are expected to migrate to SNSs. However, the lack of differences between the U.K. and Italian participants in terms of what influences risky online selfpresentation points to the pervasiveness of cyberculture ${ }^{46}$ and the possibility that internet cultures exact more influence than one's nationality ${ }^{47}$. This is certainly a promising area for future research.

There are some limitations to our findings. First, our samples were not representative of all British or Italian internet users. Research with participants from other cultures could determine if there are more widespread cultural differences in risky online posting behavior. Additionally, the self-monitoring and impulsiveness scales were focussed on offline behaviour and therefore may not reflect how individuals regulate their behaviour online. Since no online self-monitoring scale appears to exist this is a further area of potential future research.

What our results nicely reveal is that young people can behave both spontaneously and deliberately in their risky online postings on SNSs depending on the situation 48,49 . Furthermore, postings, that may be viewed as impulsive (i.e. drug consumption), may turn out 
A cross-cultural study of risky online self-presentation

to represent deliberate choices that are driven by people's self-monitoring strategy. More deliberative risky decision making has been shown to result in higher rates of risk-taking in online situations by adolescents and young adults ${ }^{50,51}$. Our findings support these previous studies, highlighting that the deliberate consideration of risks and rewards can result in potentially negative outcomes. These important revelations about young adult's online selfpresentation behaviour have not previously been considered.

While young adults tend to focus less on being employable and are, therefore, less concerned about the potential future use of the information that can be harvested online 5,28 , many individuals come to regret previous online disclosures ${ }^{49}, 52$. Consequently, further research will not only enable better understanding of this counterintuitive behaviour, but help to develop educational and technological strategies to enable young people to more appropriately manage their online self-presentation in order to avoid future regret and unfavourable consequences. 
A cross-cultural study of risky online self-presentation

\section{References}

1. Yang CC, Brown BB. Online self-presentation on Facebook and self-development during the college transition; 2016. Journal of Youth and Adolescence; 45: 402-416

2. Moll R, Pieschl S, Broome R. Trust into collective privacy? The role of subjective theories for self-disclosure in online communication. Societies 2014; 4: 770-784

3. Drouin M, Miller D. Why do people record and post illegal material? Excessive social media use, psychological disorder, or both? Computers in Human Behavior 2015; 48: $608-614$

4. Morgan EM, Snelson C, Elison-Bowers P. Image and video disclosure of substance use on social media websites. Computers in Human Behavior 2010; 26: 1405-1411

5. Nosko A, Wood E, Molema S. All about me: Disclosure in online social networking profiles: The case of Facebook. Computers in Human Behavior 2010; 26: 406-418

6. Peluchette J, Karl K. Examining students' intended image on Facebook: "What were they thinking?!”. Journal of Education for Business 2010; 85: 30-37

7. Sarabia I, Estevez A. Sexualized behaviors on Facebook. Computers in Human Behavior 2015; 61: 219-226

8. Haddon L, Livingstone S, the EU Kids Online Network. (2012). EU Kids Online: National Perspectives. EU Kids Online and the London School of Economics \& Political Science. London, U.K. Retrieved from http://eprints.1se.ac.uk/46878/

9. Peluchette J, Karl K. Social Networking Profiles: An Examination of Student Attitudes Regarding Use and Appropriateness of Content. Cyberpsychology \& Behavior 2008; 11: 95-97

10. Beeger B. (2007). Soziale Netzwerke: Karrierekiller im Internet 
A cross-cultural study of risky online self-presentation

11. Cerasaro A. (2008). Employers Defy Privacy by Using Facebook. Tennessee Journalist. Retrieved from http://njn.com/2008/apr/08/employers-defy-privacybyusin/

12. Simpson I. (2015, February 20). Maryland prison officials fired for Facebook joke about being groped. Huffington Post. Retrieved from http://www.huffingtonpost.com/2015/02/20/maryland-prisonsofficial_n_6722366.html

13. Shaw D. (2013, April 9). Paris Brown: Kent PCC resigns after Twitter row. Retrieved from http://www.bbc.co.uk/news/uk-england-22083032

14. Kingkade T. (2015, December 16). Colorado college suspends student for six months over Yik Yak post. Retrieved from http://www.huffingtonpost.com/entry/coloradocollege-yik-yak_us_56718ab1e4b0648fe301b019

15. Subrahmanyam K, Reich SM, Waechter N, Espinoza G. Online and offline social networks: Use of social networking sites by emerging adults. Journal of Applied Developmental Psychology 2008; 29: 420-433

16. Marder B, Joinson A, Shankar A, Thirlaway K, Strength matters: Self-presentation to the strongest audience rather than lowest common denominator when faced with multiple audiences in social network sites. Computers in Human Behavior 2016; 61: $56-62$

17. Snyder M, Gangestad S. On the Nature of Self-Monitoring: Matters of Assessment, Matters of Validity. Journal of Personality and Social Psychology 1986; 51: 125-139

18. Snyder M. (1987) Public appearances/private realities: The psychology of selfmonitoring. New York: Freeman 
A cross-cultural study of risky online self-presentation

19. Karl K, Peluchette J, Schlaegel C. Who's posting Facebook faux pas? A cross-cultural examination of personality differences. International Journal of Selection \& Assessment 2010; 18: 174-186

20. Rosenberg J, Egbert N. Online impression management: Personality traits and concerns for secondary goals as predictors of self-presentation tactics on Facebook. Journal of Computer-Mediated Communication 2011; 17: 1-18

21. Kobayashi T, Boase J. Tele-cocooning: Mobile texting and social scope. Journal of computer-mediated communication 2014; 19: 681-696

22. Brandtzæg PB, Heim J. Why people use social networking sites. Lecture Notes in Computer Science 2009; 5621: 143-152

23. Jackson LA, Wang JL. Cultural differences in social network use: A comparative study of China and the United States. Computers in Human Behavior 2013; 29: 910921

24. Al Omoush KHS, Yaseen S.G, Alma'aitah MA. The impact of Arab cultural values on online social networking: The case of Facebook. Computers in Human Behavior 2012: 28: 2387-2399

25. Recabarren M, Nassbaum M, Leira C. Cultural divide and the internet. Computers in Human Behavior 2008; 24: 2917-2926

26. Hofstede G, Hofstede GJ, Minkov M. (2010) Cultures and Organizations: Software of the Mind (Rev. 3rd ed.). New York: McGraw-Hill

27. Hofstede G. (2001) Culture's consequences: Comparing values, behaviors, institutions and organizations across nations. Thousand Oaks, CA: Sage

28. Chau PYK, Cole M, Massey AP, Montoya-Weiss M, O'Keefe RM. (2002). Cultural differences in the online behaviour of consumers. Communications of the ACM 2002; 45: 138-143 
A cross-cultural study of risky online self-presentation

29. Ten most searched for social networking sites by country (2015). Retrieved from http://www.digitalstrategyconsulting.com/intelligence/2013/12/top_10_most_searche d_for_social_networks_by_country.php

30. Hofstede G, Minkov M. (2013) Value Survey Module (VSM) Manual

31. Bodroza B, Jovanovic T. Validation of the new scale for measuring behaviours of Facebook users: Psycho-Social Aspects of Facebook Use (PSAFU). Computers in Human Behavior 2016; 54: 425-435

32. Gadermann AM, Guhn M, Zumbo BD. Estimating ordinal reliability for Likert-type and ordinal item response data: A conceptual, empirical, and practical guide. Practical Assessment Research \& Evaluation 2012; 17: 1-13

33. Eysenck SBG, Pearson PR, Easting G, Allsopp JF. Age norms for impulsiveness, venturesomeness and empathy in adults. Personality and Individual Differences 1985; 6: $613-419$

34. The demographics of social media users. (2015) Retrieved from http://www.pewinternet.org/2015/08/19/the-demographics-of-social-media-users/

35. Mottram AJ, Fleming MJ. Extraversion, Impulsivity and online group membership as predictors of problematic internet use. Cyberpsychology \& Behavior 2009; 12: 319321

36. Jeske D, Briggs P, Coventry L. Exploring the relationship between impulsivity and decision making on mobile devices. Personal \& Ubiquitous Computing 2016; 20 : 545-557

37. Zhang Y, Mei S, Jingxin Chae LL, Li J, Du H. The relationship between impulsivity and internet addiction in Chinese college students: A moderated mediation analysis of meaning in life and self-esteem. PLOS One 2015; 10: 1-13 
A cross-cultural study of risky online self-presentation

38. Zuckerman M, Kuhlman DM. Personality and risk taking: Common biosocial factors. Journal of Personality 2000; 68: 999-1029

39. Krasnova H, Kolesnikova E, Guenther O. "It won't happen to me!": Self-disclosure in online social networks. AMCIS 2009 Proceedings. Paper 343. Retrieved from http://aisel.aisnet.org/amcis2009/343

40. Leone C, Corte V. Concern for self-presentation and self-congruence: Selfmonitoring, Machiavellianism, and social conflicts. Social Behavior \& Personality 1994; $22: 305-312$

41. Petronio S. (2002) Boundaries of privacy: Dialectics of disclosure. New York: State University of New York Press

42. Deardorff J, Gonzales NA, Christopher FS, Roosa MW, Millsap RE. Early puberty and adolescent pregnancy: The influence of alcohol use. Paediatrics 2005; 116: 14511456

43. Kleop M, Guney N, Çok F, Simsek OF. Motives for risk taking in adolescence: A cross-cultural study. Journal of Adolescence 2007; 32: 135-151

44. Steinberg L. A social neurobiological perspective on adolescent risk taking. Developmental Review 2008; 28: 78-106

45. Measham F, Brain K. 'Binge' drinking, British alcohol policy and then new culture of intoxication. Crime, Media \& Culture 2005; 1: 262-283

46. Bell D. (2007). Cyberculture Theorists: Manuel Castells \& Donna Harraway. Routledge: Abingdon, U.K.

47. Macfayden LP, Roche J, Doff S. (2004). Communication Across Cultures in Cyberspace: A Bibliographical Review of Intercultural Communication Online. LIT Verlag: Münster. Retrieved from https://core.ac.uk/download/pdf/12174297.pdf 
A cross-cultural study of risky online self-presentation

48. Van Gool E, Van Ouytsel J, Ponnet K, Walrave M. (2015). To share or not to share? Adolescent's self-disclosure about peer relationships on Facebook: An application of the Prototype Willingness Model. Computers in Human Behavior 2015; 44: 230-239

49. Wang Y, Leon PG, Chen X, Komandur S, Norice G. From Facebook regrets to Facebook privacy nudges. Ohio State Law Journal 2013; 74: 1307-1355

50. White CM, Gummerum M, Hanoch Y. Adolescents` and Young Adults` Online Risk Taking: The Role of Gist and Verbatim Representations. Risk Analysis 2015; 35 : $1407-1422$

51. White CM, Gummerum M, Hanoch Y. Framing of Online Risk: Young Adults' and Adolescents' Representations of Risky Gambles. Decision 2016; DOI: http://dx.doi.org/10.1037/dec0000066

52. Dhir A, Kaur P, Chen S, Lonka K. Understanding online regret experience in Facebook use - Effects of brand participation, accessibility and problematic use. Computers in Human Behavior 2016; 59: 420-430 
A cross-cultural study of risky online self-presentation

Table 1. Mean scores (and standard deviation in parenthesis) and results of the independent samples $t$-test for risky online self-disclosure in the four content areas for the British and Italian participants

\begin{tabular}{lccc} 
Risky Content Type & British & Italian & $t, d f, p$ \\
\hline Alcohol/Drug content & $7.00(6.83)$ & $3.82(5.71)$ & $3.35,167.59, .001$ \\
Sexual content & $7.65(10.90)$ & $5.08(8.18)$ & $1.77,157.80, .079$ \\
Personal content & $1.46(2.60)$ & $3.61(3.95)$ & $-.425,155.40,<.001$ \\
Offensive content & $12.99(15.50)$ & $24.93(26.45)$ & $-3.68,144.84,<.001$ \\
\hline
\end{tabular}


A cross-cultural study of risky online self-presentation

Table 2. Country scores for sub-scales of the Values Survey Model for Britons and Italians

\begin{tabular}{lcc} 
VSM sub-scale & Britain & Italy \\
\hline Power Distance & 31.99 & 22.42 \\
Individualism & 38.58 & 38.08 \\
Masculinity & 8.01 & 45.38 \\
Uncertainty Avoidance & 13.81 & 38.57 \\
Long-term Orientation & 40.44 & 8.07 \\
Indulgence vs Restraint & 72.52 & 62.64 \\
\hline
\end{tabular}


A cross-cultural study of risky online self-presentation

Table 3. Mean scores (and standard deviation in parenthesis) and independent samples t-test results for self-monitoring, PSAFU, and impulsiveness for British and Italian participants.

\begin{tabular}{lccc} 
Scale & British & Italian & $t, d f, p$ \\
\hline $\begin{array}{l}\text { Number of SNS } \\
\text { Used }\end{array}$ & $5.30(1.47)$ & $4.24(1.34$ & $4.98,176,<.001$ \\
Time Weekly on & $15.72(8.58)$ & $13.96(7.21)$ & $.15,176, .140$ \\
SNS & $9.78(2.83)$ & $9.01(3.12)$ & $1.77,177, .079$ \\
Self-Monitoring & $26.70(6.57)$ & $20.77(7.35)$ & $5.72,177,<.001$ \\
PSAFU & $8.21(4.75)$ & $6.87(3.87)$ & $1.94,176, .054$ \\
Impulsiveness & & & \\
\hline
\end{tabular}


A cross-cultural study of risky online self-presentation

Table 4. Correlations between risky self-disclosure (alcohol/drugs, sexual, personal, offensive), self-monitoring, PSAFU, and Impulsiveness for the British sample

\begin{tabular}{|c|c|c|c|c|c|c|c|c|c|}
\hline & 1 & 2 & 3 & 4 & 5 & 6 & 7 & 8 & 9 \\
\hline \multicolumn{10}{|l|}{$\begin{array}{l}\text { 1. Weekly Time } \\
\text { on SNS }\end{array}$} \\
\hline 2.No. of SNSs & $.56 * *$ & & & & & & & & \\
\hline $\begin{array}{l}\text { 3.Alcohol/Drug } \\
\text { Disclosure }\end{array}$ & .17 & .13 & & & & & & & \\
\hline $\begin{array}{l}\text { 4.Sexual } \\
\text { Disclosure }\end{array}$ & $.27 *$ & .18 & $.41 * *$ & & & & & & \\
\hline $\begin{array}{l}\text { 5.Personal } \\
\text { Disclosure }\end{array}$ & .20 & .14 & $.33^{*}$ & .15 & & & & & \\
\hline $\begin{array}{l}\text { 6.Offensive } \\
\text { Disclosure }\end{array}$ & .05 & -.001 & $.30 * *$ & $.23^{*}$ & $.30 * *$ & & & & \\
\hline $\begin{array}{l}\text { 7.Self- } \\
\text { presentation }\end{array}$ & .13 & .20 & -.04 & -.05 & .01 & $-.39 * *$ & & & \\
\hline $\begin{array}{l}\text { 8.Self- } \\
\text { monitoring }\end{array}$ & .09 & -.02 & $.31 * *$ & $.23^{*}$ & $.30 * *$ & .01 & .18 & & \\
\hline 9.Impulsivity & .16 & .07 & $.29 * *$ & .09 & $.30 * *$ & $.28 * *$ & .10 & $.33 * *$ & \\
\hline
\end{tabular}


A cross-cultural study of risky online self-presentation

Table 5. Correlations between risky content area postings (alcohol/drugs, sexual, personal, offensive), self-monitoring, PSAFU, and Impulsiveness for the Italian sample.

\begin{tabular}{|c|c|c|c|c|c|c|c|c|c|}
\hline & 1 & 2 & 3 & 4 & 5 & 6 & 7 & 8 & 9 \\
\hline \multicolumn{10}{|l|}{$\begin{array}{l}\text { 1. Weekly Time } \\
\text { on SNS }\end{array}$} \\
\hline 2.No. of SNSs & $.33 * *$ & & & & & & & & \\
\hline $\begin{array}{l}\text { 3.Alcohol/Drug } \\
\text { Disclosure }\end{array}$ & $.26^{*}$ & .001 & & & & & & & \\
\hline $\begin{array}{l}\text { 4.Sexual } \\
\text { Disclosure }\end{array}$ & $.25 *$ & .12 & .19 & & & & & & \\
\hline $\begin{array}{l}\text { 5.Personal } \\
\text { Disclosure }\end{array}$ & .21 & -.01 & .05 & $.21 *$ & & & & & \\
\hline $\begin{array}{l}\text { 6.Offensive } \\
\text { Disclosure }\end{array}$ & .15 & .04 & $.22 *$ & $.46^{* *}$ & $.32 * *$ & & & & \\
\hline $\begin{array}{l}\text { 7.Self- } \\
\text { presentation }\end{array}$ & .10 & .17 & .09 & .03 & .19 & .20 & & & \\
\hline $\begin{array}{l}\text { 8.Self- } \\
\text { monitoring }\end{array}$ & .07 & -.08 & $.26^{*}$ & .07 & $.24 *$ & $.21 *$ & .11 & & \\
\hline 9.Impulsivity & .20 & .07 & $.27 *$ & .07 & .17 & $.24 *$ & .14 & $.21 *$ & \\
\hline
\end{tabular}


A cross-cultural study of risky online self-presentation

Table 6. Results of Regression Analysis Predicting Risky Online Self-Presentation $\dagger$ B $95 \%$ Wald confidence

Predictors

Intercept

Nationality

UK

Italy

Impulsiveness

Self-Monitoring

Self-Presentation

Weekly time online

Risk type

Alcohol/Drugs

Sexual content

Personal information

Offensive content

Nationality x Impulsiveness

UK x Impulsiveness

Italy x Impulsiveness

Nationality x Self-Monitoring

UK x Self-Monitoring

Italy x Self-Monitoring

Impulsiveness x Self-Monitoring

Country x Risk Type x Impulsiveness

UK x Alcohol/Drugs x Impulsiveness
0

0

$.43(.18)^{*}$

$[.07, .79]$

$.07(.03)^{*}$

$[.004, .14]$

$.15(.06)^{*}$

$[.03, .27]$

$-.01(.01)$

$[-.03, .02]$

$.02(.01)^{*}$

$[.003, .03]$

0

0

$.21(.14)$

$[-.06, .47]$

$-.68(.15)^{* *}$

$[-.98,-.39]$

$1.35(.13)^{* *}$

$[1.10,1.61]$

0

0

$-.004(.04)$

$[-.09, .08]$

0

0

-.07 (.06)

$[-.19, .06]$

$-.005(.01)$

$[-.02, .01]$ 
A cross-cultural study of risky online self-presentation

UK x Sexual content x Impulsiveness

UK x Personal information $\mathrm{x}$ Impulsiveness

UK x Offensive content x Impulsiveness

Italy x Alcohol/Drugs x Impulsiveness

Italy x Sexual content x Impulsiveness

Italy x Personal information x Impulsiveness

Italy x Offensive content x Impulsiveness

Country x Risk Type x Self-Monitoring

UK x Alcohol/Drugs x Self-Monitoring

UK x Sexual content x Self-Monitoring

UK x Personal information x Self-Monitoring

UK x Offensive content x Self-Monitoring

Italy x Alcohol/Drugs x Self-Monitoring

Italy x Sexual content x Self-Monitoring

Italy x Personal information x Self-Monitoring

Italy x Offensive content x Self-Monitoring
$-.06(.04)$

$[-.14, .02]$

-.03 (.04)

$[-.11, .06]$

$-.01(.04)$

$[-.08, .06]$

0

-.05 (.04)

$[-.13, .04]$

$-.04(.04)$

$[-.12, .05]$

$-.02(.04)$

$[-.09, .06]$

0

.04 (.07)

$[-.12, .18]$

-.05 (.08)

$[-.20, .11]$

$-.16(.06)^{*}$

$[-.28,-.05]$

0

-.05 (.04)

$[-.14, .03]$

$.01(.06)$

$[-.12, .13]$

$-.02(.05)$

$\uparrow$ Regression analysis predicting risky online self-presentation was modelled using

Generalized Estimating Equations (GEE) assuming a Poisson distribution for the outcome $* p<.05, * * p<.001$ 